\title{
FEMINISTAS? NÃO, FEMININAS! ANALISANDO VISÕES SOBRE O FEMINISMO, NO DISCURSO DE MULHERES QUE VIVENCIARAM O AUGE DO MOVIMENTO FEMINISTA BRASILEIRO
}

\section{FEMINISTS? NO, FEMININES! AN ANALYSIS OF VIEWS ABOUT FEMINISM IN DISCOURSE OF WOMEN WHO EXPERIENCED THE HEYDAY OF BRAZILIAN FEMINIST MOVEMENT}

\author{
Juliana Cristina Teixeira ${ }^{1}$, Mônica Carvalho Alves Cappelle ${ }^{2}$ \\ e Maria de Lourdes Souza Oliveira ${ }^{3}$
}

Recebido em: 14/04/2011

Aprovado em: 26/12/2011

\section{RESUMO}

O feminismo, como movimento social, surge em um contexto de ideias iluministas e transformadoras presentes nas Revoluções Francesa e Americana. No Brasil, o movimento teve suas peculiaridades. Algumas contribuições, no que se refere a avanços na luta contra a condição de opressão de mulheres na sociedade, são significativas. No entanto, são muitas as visões pejorativas sobre o movimento veiculadas pelo senso comum. No presente artigo, por meio de entrevistas em profundidade, buscou-se investigar a percepção de algumas empresárias de uma cidade de Minas Gerais sobre o feminismo. É importante ressaltar que se trata de mulheres que vivenciaram o auge do movimento feminista brasileiro. Como principal resultado, observa-se que, mesmo tendo vivenciado períodos de lutas feministas e tendo se beneficiado de várias conquistas, as mulheres investigadas corroboram com visões reducionistas e limitadas do feminismo, chegando até mesmo a rejeitá-lo, usando o bordão de serem femininas, e não feministas. Essas afirmações contribuem para a noção polarizada predominante no senso comum, de que mulheres feministas não necessariamente são femininas, apropriando indevidamente o conceito de feminismo.

Palavras-chave: Feministas; Femininas; Visões; Movimento feminista.

\begin{abstract}
Feminism as a social movement emerges in a context of enlightenment and transforming ideas of French and American Revolutions. In Brazil, the movement had its own peculiarities and its contributions in respect of advances against the condition of oppression of women in society are significant. However, there are many derogatory views about the movement conveyed by common sense. In this paper, through extensive interviews with female entrepreneurs from a city of Minas Gerais, we aimed to examine the view that women who experienced the heyday of Brazilian feminist movement, have about feminism. As main result, we see that even these women agree with limited and reductionist views about feminism, reaching even to reject it in favor of being feminine and not feminist, improperly appropriating the concept of feminism.
\end{abstract}

Keywords: Feminists; Feminines; Views; Feminist movement.

\footnotetext{
Doutoranda em Administração pelo Centro de Pós-Graduação e Pesquisas em Administração da Universidade Federal de Minas Gerais - CEPEAD/ UFMG. Mestre em Administração pelo PPGA da Universidade Federal de Lavras - UFLA. Pesquisadora do NEOS

E-mail: julianacteixeira@yahoo.com.br

${ }^{2}$ Doutora em Administração pela Universidade Federal de Minas Gerais. Professora da Universidade Federal de Lavras. E-mail: edmo@dae.ufla,br

${ }^{3}$ Doutora em Ciências Sociais pela Universidade Federal Rural do Rio de Janeiro. Professora da Universidade Federal de Lavras.
}

E-mail: julinet@dae.ufla.br 


\section{Introdução}

O feminismo, como movimento social, surge em um contexto de ideias iluministas e transformadoras presentes na Revoluções Francesa e Americana. Com o fortalecimento dos movimentos feministas, o panorama das Ciências Sociais passou a ser tensionado e alterado para que respondesse às novas interpelações, incorporando, prioritariamente a temática da desigualdade social entre os sexos. Deste modo, a temática ganhou visibilidade e força, após um longo caminho percorrido desde os anos 70, questionando paradigmas das Ciências Sociais (COSTA, 1994).

No Brasil, o movimento teve suas peculiaridades no que se refere a uma vinculação a decisões participativas e democráticas, podendo ser considerado um dos movimentos sociais com melhor desempenho do país. Suas contribuições, em relação a avanços na luta contra a condição de opressão das mulheres na sociedade, são significativas. No país, o auge do movimento se dá nos anos 70 e é impulsionado por grupos de mulheres de classe média, em geral com nível superior de instrução, que trazem inspirações do feminismo europeu e norte-americano (BARSTED, 1994).

O termo foi cunhado originalmente para caricaturar e para humilhar mulheres que eram engajadas nas lutas por justiça, igualdade e liberdade, e tal origem até hoje faz com que sejam distorcidos sua natureza e seus objetivos (HAWKESWORTH, 2006). Uma vez que "[...] na cabeça de muitos, o feminismo se confundiu com a luta pelo direito das mulheres, interpretado de forma restrita - o direito de ganhar seu próprio sustento, de receber seu próprio salário, direito à educação, de se profissionalizar e de votar" (HAWKESWORTH, 2006, p.747).

As visões pejorativas sobre o movimento, veiculadas pelo sen- so comum, são muitas. Hawkesworth (2006) afirma que depois que as mulheres brancas conquistaram direitos históricos com o movimento feminista no século XIX e no início do XX, o termo feminismo pareceu obsoleto, irrelevante e desnecessário. A autora complementa, esclarecendo, que as mulheres que continuassem se considerando feministas poderiam ser avaliadas como tolas e estridentes, e pondera ainda que algumas mulheres utilizam a tática de assassinar o termo para que o rótulo feminista continue fortemente caricaturado, e elas possam continuar seu trabalho sem carregá-lo.

Diante dessa problematização inicial, a questão central que norteia o presente artigo é como essas mulheres percebem a trajetória do movimento feminista no Brasil. Nesse sentido, objetiva-se investigar a percepção de algumas empresárias de uma cidade de Minas Gerais sobre o feminismo, destacando que se trata de mulheres que vivenciaram o auge desse movimento e que pertencem à classe inicialmente sensibilizada pelos recursos simbólicos do feminismo no país: a classe média.

Para o alcance do objetivo, foi realizada inicialmente uma revisão bibliográfica sobre o feminismo, as principais demandas conquistadas, algumas trajetórias históricas e alguns conceitos fundamentais envolvidos. Após essa inserção, foi realizada a pesquisa de campo, descrita no item quatro deste artigo.

$\mathrm{O}$ artigo estrutura-se da seguinte forma: no item dois, é feita uma revisão bibliográfica sobre o feminismo, as visões atribuídas ao mesmo, e sobre o que é ser feminista, sendo tecidas algumas considerações acerca do feminismo como movimento social. No item três, é feita uma breve revisão sobre a trajetória do movimento feminista brasileiro. No item quatro, apresenta-se a metodologia utilizada no presente estudo. No item cinco, são apresentadas as análises dos resultados 
obtidos com a pesquisa, traçando-se algumas dimensões da visão reducionista que as mulheres apresentaram sobre o movimento feminista. Por fim, no item cinco, são feitas as considerações finais.

\section{Os vários feminismos segundo o senso comum e as teorias}

Pode-se dizer que há diversos feminismos, e, na tentativa de formular uma definição que represente uma unidade entre os mesmos, Franchietto, Cavalcanti e Heilborn (1981) destacam a reivindicação, para as mulheres, de um espaço da atuação política, ressaltando sua condição histórica de submissão a uma ordem dominantemente masculina. $\mathrm{O}$ feminismo pode ser concebido como uma ideia, como um conjunto de convicções, como uma ideologia, como um movimento social e também como uma práxis.

Como práxis, ser feminista implica passar por um processo complexo, que envolve autoconhecimento, modos de vestir e de se comportar, relações com amigos e com amantes, bem como mudanças materiais e sociais (HAWKESWORTH, 2006). "O modelo de práxis do feminismo insiste que o feminismo nunca é fixo ou estático. [...] o feminismo nunca é um projeto terminado; cresce e muda com as condições mutantes da opressão das mulheres" (HAWKESWORTH, 2006, p. 751).

A noção de feminismo como práxis se contrapõe a sua visão como movimento social. A ideia de movimento indica a existência de "líderes formadores de consciência e motivadores de indivíduos à ação, a noção de práxis sugere que o feminismo surge autonomamente dentro dos indivíduos, na medida em que estes lutam com as contradições em suas vidas (HAWKESWORTH, 2006, p.750). Ou seja, o feminismo, nessa concepção, não seria um movimento social, mas sim uma prática presente na vida das mulheres, enquanto estivessem autonomamente lidando com os efeitos da dominação masculina em suas vidas.
Já no âmbito da teoria, considera-se o feminismo como um "[...] instrumento teórico que permite dar conta da construção de gênero como fonte de poder e de hierarquia que impacta mais negativamente sobre a mulher. É a lente através da qual as diferentes experiências das mulheres podem ser analisadas criticamente [...]" (BAIRROS, 1995, p. 462). Em seu corpo teórico, pode-se dizer que o feminismo contribuiu também para fazer coro com as críticas à ciência tradicional, moderna e positivista (NOGUEIRA, 2001).

Considera-se também que a articulação feminista apresenta-se como uma catalisadora de mudanças sociais direcionadas não só para as mulheres, mas também para a sociedade. Nesse sentido, há vários feminismos, que envolvem múltiplos interesses e que precisam tratar também da própria diversidade entre as mulheres, seja racial, étnica, seja de condição socioeconômica, de orientação sexual, de geração e de cultura. Tais demandas se relacionam com a superação de uma imagem da feminista caracterizada como branca, de classe média e intelectual. Além disso, há uma abordagem plural em relação aos espaços políticos que são conquistados pelas mulheres, na sociedade (RIBEIRO, 2006). feminismo

Por fim, pode se compreender o

[...] em primeiro lugar, como uma arena, depois, como um campo teórico, uma prática interpretativa e, por fim, como um lugar político. Se o feminismo, como prática política, já nasce como uma arena, lugar para onde confluem discursos vindos de muitos lugares, cena aberta de disputa e negociação de poder, com o visível alargamento do campo nas últimas décadas, esta sua característica se intensifica (SCHMIDT, 2004, p.17).

Além da intensificação dessa característica, percebe-se, nas últimas décadas, um aumento sem precedentes do 
feminismo, embora muitos tentem declarar sua morte, pois foram ampliados os espaços de atuação das feministas, não mais restritos a ruas e grupos autônomos, ampliando-se para outras arenas culturais, sociais e políticas, bem como para a academia, instituições governamentais e também ONG's, entre outros espaços (ALVAREZ, 1998). Ainda hoje, por meio de "um trabalho por demais invisível de ativistas feministas pelo mundo, o feminismo emerge em múltiplas lutas que raramente chamam a atenção da imprensa" (HAWKESWORTH, 2006, p.738). Fora isso, estritamente no contexto brasileiro, destacam-se as vivacidades do feminismo e a sua trajetória de reformulações, bem como o fato de trazer novas personagens para a cena política (RIBEIRO, 2006).

A consideração de que o feminismo morreu também se relaciona com o que se pode chamar de tabu do feminismo. Duarte (2003) afirma que há no Brasil, diferentemente do que ocorre em outros países, uma forte resistência em relação à palavra feminismo, diante da qual a autora se posiciona desfavoravelmente, defendendo que a vitória do movimento seja "[...] inquestionável quando se constata que suas bandeiras mais radicais tornaram-se parte integrante da sociedade, como, por exemplo, mulher frequentar universidade, escolher profissão, receber salários iguais, candidatar-se ao que quiser [...]" (DUARTE, 2003, p.151).

Assim, mesmo as lutas feministas que podem ser consideradas mais radicais foram parte fundamental da conquista de direitos essenciais para as mulheres. Não obstante, era de se esperar que as mulheres tivessem, então, uma visão positiva dessas lutas. Contudo, Duarte (2003) considera que as principais vitórias do movimento feminista foram as conquistas que hoje fazem parte de uma realidade que já foi um dia um sonho utópico. Porém, sua maior derrota foi a construção social do preconceito, prejudicando que seja visto como motivo de orgulho para a maioria das mulheres e fazendo com que o termo feminista pudesse ser considerado como "sinônimo de mulher mal amada, machona, feia e, a gota d'água, o oposto de feminina" (DUARTE, 2003, p.152). Nesse sentido, pode-se supor a existência de visões reducionistas do feminismo, no que se refere a considerá-lo apenas como um movimento articulado em torno de determinadas bandeiras, pois, entre outros fatores, há um senso comum limitado sobre a história do feminismo, o que normalmente faz com que tudo o que ultrapasse a luta pelo voto, os anos 1970 e conquistas mais recentes seja relegado a notas de rodapé (DUARTE, 2003).

Tais visões reducionistas levam justamente à declaração recorrente de que o feminismo tenha morrido, ao que Hawkesworth (2006) chama de enterro prematuro do feminismo. A falta de informações sobre o feminismo resulta, por exemplo, em um tratamento do sucesso do ativismo feminista como sendo um único movimento, o que favorece a utilização de metáforas que atribuem ao mesmo, um tempo de vida determinado, um nascimento e uma morte (HAWKESWORTH, 2006). Essas declarações de morte parecem reforçar não só a existência de um tabu do feminismo, mas também, considera Hawkesworth (2006), a utilização de sinais alegóricos para a morte do feminismo como forma de identificar um perigo a ser eliminado, relacionando o "enterro retórico do feminismo contemporâneo a um esforço contínuo para minar as lutas feministas por justiça social" (HAWKESWORTH, 2006, p. 740). A autora se questiona "como conceitualizar a morte de fenômenos tão diversos quanto as representações mentais, os preceitos morais, os modos de ser e as formações sociais" (HAWKESWORTH, 2006, p. 746) que representam o feminismo.

Dialogando com a temática sobre a morte do feminismo proposta por Hawkesworth, Ribeiro (2006) afirma 
que, analisando tanto o ativismo brasileiro e latino-americano-caribenho, quanto outras vivências internacionais, não é hora de decretar o fim do movimento. Ao contrário, considera que este não morrerá, por não deixar de existir como um fio condutor para mudanças, pois, ao invés disso, o feminismo se transforma e se moderniza. Pode-se considerar, na verdade, o surgimento de novos conceitos e práticas que mantêm sua capacidade de retomada e de reinserção (RIBEIRO, 2006). Além disso, "[...] o convite a imaginar o feminismo morto é um convite ao repúdio da igualdade sexual e da justiça de gênero, a aceitar as relações de poder assimétricas entre homens e mulheres como a ordem natural das coisas" (HAWKESWORTH, 2006, p. 754).

Como resposta às alegações de que o movimento feminista acabou, Costa (2005) defende que o mesmo nunca esteve tão vivo e tão mobilizado como no início deste século. A autora considera que o feminismo "talvez tenha mudado de cara, já não queima sutiã, raramente faz passeata e panfletagem, o que não significa dizer que tenha perdido sua radicalidade, abandonado suas lutas, acomodado-se com as conquistas obtidas ou mesmo se institucionalizado" (COSTA, 2005, p. 9).

A autora avalia que o feminismo tenha mudado não somente se comparado ao movimento sufragista e emancipacionista do século XIX, mas também relativamente aos movimentos dos anos 60 à 90. Nessa trajetória, o movimento sempre causou fricções. Com a Igreja, por exemplo, apesar de haver uma relativa aliança, havia um ponto de tensão relacionado à defesa do aborto por parte das feministas. Com os militantes comunistas, criavam-se pontos de tensão relacionados ao debate entre lutas mais amplas versus lutas mais específicas. Nesse aspecto, os militantes comunistas buscavam dar prioridade a lutas mais gerais do que a reivindicações feministas, além de utilizar como estratégia impedir a participação de lésbicas no movimento (CORRÊA, 2001, p.14). Para a direita, o feminismo era considerado algo imoral e perigoso; para a esquerda, era reformismo burguês. Até mesmo no campo teórico, a temática feminista é fluida e encontra uma rejeição prevalecente entre especialistas, que alegam sua inclinação separatista como fonte de demarcação de um território próprio para o estudo das mulheres e que defendem a busca de uma transversalidade e de um reconhecimento da onipresença de diferentes campos disciplinares das hierarquias baseadas no sexo (COSTA, 1994). Mas, mesmo diante de tais fricções, o "feminismo foi se expandindo dentro desse quadro geral de mobilizações diferenciadas. Conviveu com a diversidade, sem negar sua particularidade" (SARTI, 1998, p.6). Dessa forma, "as dicotomias entre lutas gerais e lutas específicas [...], presentes nessas disputas, falam de poderes e de conflitos" (PEDRO, 2006, p. 249 , grifo do autor). Assim são os debates e conflitos existentes em relação ao feminismo, o que corrobora para a formação de diferentes concepções e visões sobre o mesmo.

Como movimento social, em seu primeiro momento, o movimento feminista levanta uma bandeira por direitos sociais e políticos das mulheres, sendo seu auge a luta sufragista. Há a passagem por um período de desmobilização e o ressurgimento em um contexto de movimentos contestatórios nos anos 1960 , tendo como alvo a afirmação de que o pessoal é político, não apenas interessado em uma mobilização, mas também em questionar o parâmetro de político, ampliando as discussões de assuntos até então considerados privados, questionando o pensamento liberal (COSTA, 2005). Vale ressaltar que "o conceito de público diz respeito ao Estado e às suas instituições, à economia e a tudo mais identificado como político. Já o privado se relaciona com a vida doméstica, familiar e sexual, identificado como o pessoal, alheio à política" (COSTA, 2005, p. 10). 
Desse modo, Bairros (1995) considera que a afirmação de que o pessoal é político passou a ser um conceito básico do feminismo, descartando visões de que os problemas de mulher são apenas pessoais e restritos ao âmbito privado, pois passou a se considerar as relações de poder intrínsecas às questões de gênero, mesmo que essas estivessem fora da esfera pública, da ação direta do Estado e da forma capitalista de organização da sociedade. Assim, "poder-se-ia definir como instituição política qualquer atividade estruturada" (BAIRROS, 1995, p. 460) para perpetuar a dominação masculina.

Enquanto a situação de opressão das mulheres era reduzida à esfera privada, pode-se afirmar que sua cidadania adviria do fato de serem esposas de cidadãos, ou seja, sua cidadania estaria excluída de qualquer realidade política (NOGUEIRA, 2001, p. 3). Assim, o movimento feminista destacou o caráter político da opressão às mulheres, até então vivenciada isolada e individualmente. Tal destaque chama a atenção das mulheres, pois o movimento demonstra que as circunstâncias do pessoal podem estar estruturadas em questões públicas, inserindo, na política, espaços do privado e do doméstico.

Porém é importante destacar que, apesar do caráter político da opressão das mulheres, há também que se considerar "a impossibilidade do feminismo ser formulado exclusivamente em termos políticos, por se colocar no plano da subjetividade" (SARTI, 1998, p. 9). Desse modo, a discussão que se faz no presente artigo transita tanto por questões consideradas públicas, no que se refere a formas de poder estabelecidas socialmente, quanto a dimensões subjetivas que se relacionam com a questão do feminismo, principalmente no que diz respeito à percepção que as mulheres entrevistadas apresentaram sobre o mesmo. Uma vez que, como afirma Sarti (1998), o feminismo não se reduz a questões relacionadas ao poder, mas também se relaciona a experiências subjetivas sobre o que seriam os lugares do masculino e do feminino.

\section{Revisitando brevemente a trajetó- ria do movimento feminista brasileiro}

Há a necessidade de se considerar que o movimento feminista brasileiro não aconteceu isolado nem de forma homogênea, sem sofrer influências do contexto mundial, especialmente dos movimentos feministas latino-americanos e das novas dinâmicas supranacionais (COSTA, 2005). As primeiras manifestações do feminismo no Brasil aparecem na primeira metade do século XIX, principalmente por meio da imprensa feminina. No final desse século, já se podia encontrar mulheres incorporadas a lutas sindicais por melhores salários e por melhores condições de trabalho, influenciadas por ideias anarquistas e socialistas de trabalhadores espanhóis e italianos (COSTA, 2005). Porém, mais do que essas reivindicações que eram comuns aos gêneros, havia também reivindicações pelo "combate às discriminações e aos abusos a que estavam submetidas por sua condição de gênero" (COSTA, 2005, p. 12).

Considera-se que o feminismo tenha surgido no país por iniciativa de mulheres emancipadas de classe média, sendo que as operárias já participavam antes de vários tipos de movimentos, mas restritos a reivindicações gerais. Nos anos 20, o movimento no Brasil recebe grande impulso e foca na luta pelos direitos políticos da mulher, principalmente ao voto, à educação e aos direitos trabalhistas, com grande concentração, como em todo o mundo, para a luta sufragista. Em um primeiro momento, o movimento feminista brasileiro, e também o de países da América Latina, pode ser considerado um feminismo bem comportado, sendo conservador quanto ao questionamento da divisão sexual dos papéis de gênero, pois 
acabava também por reforçar tais papéis e tais estereótipos, utilizando, como justificativa de suas demandas, virtudes domésticas e maternas. Com a ditadura militar, iniciada em 1964, os movimentos de mulheres no Brasil são silenciados, assim como outros movimentos populares. Mais importante é destacar, inclusive, que movimentos de mulheres da burguesia e da classe média apoiaram os golpes militares (COSTA, 2005).

Em um segundo momento, o movimento feminista no Brasil e na América Latina é definido como um feminismo de resistência (COSTA, 2005), iniciado nos anos 70 , como resistência das mulheres à ditadura militar (BARSTED, 1994). É na mesma década que o Brasil começa a passar por processos acelerados de mudanças sociais que culminam, dentro de um regime político autoritário, em alterações profundas no estatuto social das mulheres. Há alterações radicais nas relações entre os sexos com a migração, urbanização, aumento dos níveis de escolarização, difusão da comunicação em massa e queda na taxa de fecundidade. Há o aumento do contingente de estudantes do sexo feminino nas universidades, ainda em uma concentração segregada para as ciências humanas. Há a participação, então, de muitas dessas mulheres, cujo nível de educação foi aumentado, nas mobilizações feministas e também na produção acadêmica na área de humanas, em que preferencialmente se inseriram os estudos da mulher (COSTA, 1994).

Em seus diversos momentos, considera-se que o movimento de mulheres no Brasil assuma duas identidades; "de um lado, fazia parte do movimento contra a ditadura, já que muitas de suas militantes pertenciam a grupos de resistência; de outro, apresentava-se como um ator social novo na luta pelo reconhecimento da condição da mulher enquanto problemática social" (BARSTED, 1994, p. 40).

$\mathrm{O}$ auge do movimento feminista brasileiro se deu nos anos 70 , por di- versos motivos que podem ser considerados fatores que contribuíram para que as mulheres tivessem um papel visível na estrutura das relações sociais no Brasil. Não só inicialmente, as mulheres de classe média e de nível universitário, mas também, na metade dos anos 70, mulheres que pertenciam a classes mais baixas e que não tinham acesso à educação. Em primeiro lugar, o enfraquecimento da ditadura militar; em segundo, o aumento da participação feminina na população economicamente ativa e na ocupação de profissões de alto prestígio e, em terceiro, uma mudança religiosa. Por parte da Igreja Católica, houve um direcionamento para as necessidades das massas e para a formação de grupos comunitários muitas vezes liderados por mulheres; por parte das religiões afro-brasileiras, oferta de força libertadora em papéis considerados positivos. Há, então, uma reformulação do arquétipo de Maria a fim de abrir brechas para as mulheres assumirem papéis de liderança e de aconselhamento (DE SOUZA et al, 2000).

Já a consolidação das questões de fato feministas e das referentes às relações de gênero se dá com o processo de abertura política do país, no final dos anos 70, o que abre espaço para reivindicações no plano das políticas públicas e também para o aprofundamento das reflexões sobre gênero (SARTI, 1998). Em seguida, de acordo com Costa (2005), novos movimentos de liberação se unem ao movimento feminista para reivindicar direitos dentro de uma luta geral, como o movimento dos negros e dos homossexuais. Segundo a autora, há também uma proliferação do movimento feminista para novos grupos e novas bandeiras, como direitos reprodutivos, violência contra a mulher e sexualidade.

A diversidade foi uma característica marcante do movimento feminista no Brasil, mas sua unidade se manteve até início dos anos 80, quando a luta oposicionista ainda funcionava como um elemento de aglutinação para o mesmo (SARTI, 1998). Foi no início 
dessa década que o movimento, ampliado como movimento de mulheres, atuou ativamente contra a ditadura e a favor da democracia. Assim, as feministas, aproveitando as brechas democráticas decorrentes ainda da não declaração do fim da ditadura, passam a participar de órgãos do Estado, e inicia-se um diálogo com o poder estatal para a busca de políticas públicas destinadas a reverter o quadro de discriminação contra as mulheres (BARSTED, 1994).

Desse modo, o movimento feminista brasileiro pode ser considerado um "movimento social mais vinculado às decisões participativas e democráticas, ao permanente controle e questionamento sobre as instâncias de poder ou de formação de lideranças por parte do movimento de base" (COSTA, 2005, p. 22). Assim, criou-se, no país, um movimento feminista bastante politizado (SOARES, 1998). A problemática associada à mulher, no Brasil, foi influenciada pela existência de movimentos de liberação das mulheres nos países centrais, mas principalmente por ativos movimentos locais de mulheres que visavam a "modificar o sistema de acesso a recursos e as relações de poder entre os sexos" (COSTA, 1994, p. 403). Em um contexto de ausência de liberdades públicas e de iniquidade social, há o surgimento de um feminismo peculiar, ou seja, adequado para o Brasil, que seria direcionado primordialmente para a reivindicação de direitos sociais (COSTA, 1994).

Com as mobilizações feministas, há também a emergência da temática sob um olhar científico, centrando-se originalmente em estudos bem sucedidos, em esforços para oferecer visibilidade à mulher, recuperar sua presença na história e considerar o androcentrismo como negativo para o conhecimento científico. Nos anos 80 , a produção científica sobre a temática cresce e diversifica (COSTA, 1994). Nos anos
90, há a proliferação de várias modalidades de organizações e de identidades feministas, de mulheres pobres em associação de moradores, de operárias em sindicatos, de trabalhadoras rurais, bem como de organizações feministas de mulheres negras. Há o chamado feminismo popular, sendo importante considerar a existência de muitos feminismos e de diversidades de pontos de vista (COSTA, 2005). Além disso, "o crescimento do feminismo popular teve como consequência fundamental para o movimento amplo de mulheres a diluição das barreiras e das resistências ideológicas para com o feminismo" (COSTA, 2005, p. 19).

No início dos anos 2000, o movimento feminista brasileiro tenta ampliar a participação legitimada das mulheres nos espaços públicos e decisórios, lutando por políticas específicas e pela criação de novos espaços de interlocução. Ocorre o reconhecimento, por parte do movimento, do próprio desafio que representa o aumento de sua participação em espaços institucionalizados, podendo significar tanto um fortalecimento de sua participação como sujeito na política, como também a existência de riscos de instrumentalização de uma participação apenas ilustrativa (COSTA, 2005).

Tal esforço para ampliar a participação política das mulheres no contexto brasileiro não ocorre de forma isolada. Dentro das instituições oficiais de Estado na África, Ásia, Austrália, Europa, América Latina e América do Norte, os projetos feministas estão em andamento, viabilizados pela inserção ampla de questões de gênero nos centros de poder e pela criação de aparelhagens nacionais para as mulheres, secretarias para as mulheres e comissões pela igualdade de gênero (HAWKESWORTH, 2006, p. 738, grifo da autora), além de haver uma proliferação de ONGs feministas.

' $\mathrm{O}$ arquétipo de Maria é um estereótipo da mulher como fraca, submissa, passiva, restrita aos limites da casa e da Igreja, sem poder na esfera pública (SOUZA; BALDWIN; ROSA, 2000) 
Como um balanço, pode-se afirmar que o movimento feminista brasileiro como

[...] novo movimento social, extrapolou os limites do seu status e do próprio conceito. Foi mais além da demanda e da pressão política na defesa de seus interesses específicos. Entrou no Estado, interagiu com ele e ao mesmo tempo conseguiu permanecer como movimento autônomo. Através dos espaços aí conquistados (conselhos, secretarias, coordenadorias, ministérios etc.) elaborou e executou políticas (COSTA, 2005, p. 26, grifo do autor).

Ainda hoje, o movimento passa por novas demandas e por novos enfrentamentos, não sendo ainda consenso na sociedade brasileira. Por exemplo, a implantação de políticas especiais para mulheres enfrenta resistências tanto culturais quanto políticas. Exemplos de tais resistências são os setores que acreditam que as relações de gênero são uma ordem social estruturada por funções imutáveis na sociedade; também aqueles setores que questionam a existência atual do feminismo; e os que não consideram as desigualdades de gênero como sendo uma questão pública (COSTA, 2005).

Contudo, Carneiro (2003) afirma que o movimento de mulheres no Brasil é um dos movimentos com melhor desempenho se comparado aos movimentos sociais do país. A autora dá como exemplo o fato da Constituição de 88 contemplar cerca de $80 \%$ de suas propostas, destituindo, por exemplo, o pátrio poder. As já referidas contribuições do movimento para a democratização do Estado também são destacadas por Carneiro. Além disso, fatos importantes no país, que fazem do movimento feminista brasileiro um dos mais respeitados do mundo, segundo a autora, são: a criação de órgãos destinados à elaboração de políticas públicas; a luta contra a violência doméstica e sexual, que dei- xa a esfera do privado para fazer parte de políticas específicas; a criação de órgãos destinados à efetivação das políticas públicas voltadas para as mulheres; e as lutas no campo da sexualidade, no que se refere ao direito ao prazer, a ter ou não filhos.

Já Souza, Baldwin e Rosa (2000) destacam, dentre as temáticas para as quais contribuiu o movimento feminista no Brasil; o planejamento familiar, considerando que as feministas ajudaram para o aumento da consciência dentro do debate sobre o assunto; a questão do cuidado dos filhos, com as reivindicações para que as empresas mantivessem as creches para os filhos das trabalhadoras, aspecto este que distingue mais o movimento do país em relação aos demais; a atuação, como também destacado por Carneiro (2003), em relação à violência contra a mulher, cujo caminho a percorrer é ainda grande; e a temática do assédio sexual, sobre a qual o país despertou apenas recentemente.

Percebe-se, tentando fazer uma síntese, que há no Brasil, corroborando com o que Sarti (1988) enfatiza, duas tendências na corrente feminista de movimento das mulheres:

A primeira, mais voltada para a atuação pública das mulheres, investindo em sua organização política, concentrando-se principalmente em questões relativas ao trabalho, ao direito e à redistribuição de poder entre os sexos. Essa tendência desenvolve sobretudo uma prática de grupos de pressão. A outra vertente preocupa-se sobretudo com o terreno fluido da subjetividade, com as relações interpessoais, tendo no mundo privado seu campo privilegiado. Manifestou-se principalmente através dos grupos de estudos, de reflexão, ou convivência (SARTI, 1988, p.43).

Assim, o movimento feminista brasileiro, reconhecidamente, teve um papel importante não só para o questionamento de estruturas sociais específi- 
cas da mulher, mas referentes à sociedade como um todo, inclusive, para a instituição que se convenciona chamar de família.

\section{Caminhos metodológicos}

Para que se pudessem cumprir os objetivos propostos, foi realizado um estudo exploratório, mediante quatro entrevistas em profundidade, de uma população amostral de nove mulheres. Diante do objetivo, optou-se por pesquisa qualitativa que, entre outras questões, não conduz medições nem quantificação de resultados, buscando obter dados sobre pessoas, lugares e processos interativos, além de permitir um contato direto do pesquisador com o fenômeno social investigado (GODOY, 1995).

Na composição da amostra, foram selecionadas mulheres integrantes de um conselho feminino, um grupo organizado de mulheres que se denominam empreendedoras, por atuarem como empresárias ou como profissionais autônomas em um município do interior de Minas Gerais (optou-se por não identificar o município para preservar a identidade das entrevistadas, já que é o único grupo feminino com esse enfoque em seu território). O grupo é interligado à associação comercial e industrial do município e tem como objetivo se constituir em um espaço estimulador para as ações que as mulheres empreendedoras realizam ou pretendem realizar. $O$ foco principal é a atividade empreendedora. Nesse sentido, o grupo tem se organizado para obter e trocar informações em torno de projetos de seu interesse. O grupo foi criado em 2004 e é constituído por 12 mulheres, mas, na ocasião da pesquisa, apenas nove delas estavam participando ativamente .

Definiu-se como critério de amostragem que todas as mulheres entrevistadas tivessem nascido até 1950 , ou seja, com idade de, no mínimo, 58 anos, para que tivessem vivenciado ainda jovens, o auge do movimento feminista brasileiro, que se deu nos anos 70. Além disso, todas teriam que possuir formação universitária, para caracterizar adequadamente as mulheres que pertenciam, na época, ao primeiro grupo de mulheres sensibilizadas pelos recursos simbólicos do feminismo (SARTI, 2001). Cinco das nove ativas no grupo se enquadravam no perfil desejado. O convite para a participação na pesquisa foi feito por telefone ou por e-mail, e quatro delas se disponibilizaram a serem entrevistadas. A identificação das mulheres foi ocultada, sendo elas designadas por siglas de M1 a M4. M1 é graduada em Pedagogia, casada há trinta e três anos, tem dois filhos e é a presidente do grupo. M2 é graduada em Direito, casada há 17 anos e tem uma filha. M3 é graduada em Psicologia, solteira e não tem filhos. M4 é graduada em Engenharia, solteira e sem filhos.

As entrevistas ocorreram por meio de roteiros semiestruturados, permitindo adequação de sua condução às especificidades de cada uma das participantes. Sendo o presente estudo parte de uma pesquisa maior, o número de questões presentes no roteiro foi trinta. A duração das entrevistas foi de $1 \mathrm{~h}$ a $1 \mathrm{~h} 30 \mathrm{~min}$. Elas foram gravadas e posteriormente transcritas. A técnica de análise utilizada foi análise de conteúdo temática, mediante a busca de temas similares nos discursos das entrevistadas, e sua posterior organização em núcleos de sentido comuns.

\section{As visões das mulheres sobre o fe- minismo}

Foram apresentadas, às mulheres, questões relacionadas à opinião que as mesmas tinham sobre os movimentos feministas; ao que seria liberdade para

${ }^{2} \mathrm{O}$ presente estudo integra uma pesquisa maior que teve objetivos interligados a relações de gênero. 
elas; bem como opiniões sobre o machismo e sobre a relação entre homens e mulheres na sociedade. Considerou-se relevante questioná-las dessa maneira, dado que são mulheres que vivenciaram contextos em que o movimento feminista brasileiro teve o seu auge. É importante acrescentar que pertencem à classe dita "intelectualizada", composta por mulheres que participaram ativamente do movimento (o que não significa que elas tenham participado ativamente).

Observou-se, de uma forma geral, que mesmo mulheres que vivenciaram o movimento e as várias transformações que ocorreram em relação à ampliação de espaços conquistados, apresentam uma visão ainda muito reducionista sobre o movimento. Destacam-se algumas dimensões dessa visão limitada: a consideração de que o feminismo é o oposto de feminino, ou que ser feminista é o oposto de ser feminina; a bandeira do feminismo como tendo um caráter de segregação; uma ênfase ao caráter radical do movimento; a crença de que o movimento fez ampliar o homossexualismo, mais especificamente, o lesbianismo e do movimento feminista como forma de embrutecimento das mulheres. E, ainda que reconheçam avanços relativos à condição social da mulher, geralmente enfatizam mudanças que ocorreram em um nível interpessoal e nem tanto público, consequentemente, não citam o movimento feminista ao falar sobre tais transformações. As análises consideram conquistas individuais desconectadas do contexto, em que transparecem que bastam decisões individuais para que se conquiste autonomias. A literatura leva a aprofundar mais esta argumentação, quando se observam inserções desiguais no mercado de trabalho, sobretudo quando se tratam de mulheres negras.

Observou-se, em primeiro lugar, como já apontado acima, uma visão do feminismo polarizada em relação ao feminino. M1, por exemplo, ao ser questionada sobre o que seria a liberdade, antes mesmo que se fizesse qualquer questão sobre o movimento feminista, já afirmou que

[...] eu não sou feminista [...]. Eu sou uma mulher como todas as outras femininas, tenho coração, sofro, amo, é...percebo, é...sou muito observadora e...agora tem uma coisa que realmente...e aí a Psicologia explica... nós podemos ser mães. Nós podemos gerar vida né, dentro da gente. Então, isso aí eu acho que é a grande...a grande diferença dos homens assim né, porque o homem sente né, da gente poder...da gente ser terra...não é? Ser terra...isso é uma coisa muito forte na mulher. Ela não pode perder esta questão da maternidade de vista de jeito nenhum (M1).

Além da oposição feminismo versus feminino, observa-se, no fragmento, uma recorrência à maternidade como algo de que a mulher não possa se desvincular. Se considerarmos que os movimentos feministas levantaram a bandeira pela liberdade da mulher em decidir ter ou não filhos, pode-se talvez compreender melhor a recorrência de M1 à questão da maternidade ao falar sobre liberdade para as mulheres. Ainda, observa-se uma forte vinculação da mulher à sua característica biológica, o que pode reforçar os estereótipos femininos baseados nas diferenças de sexo.

A oposição entre feminismo e feminino se demonstra clara quando M2 é questionada sobre sua opinião sobre os movimentos feministas:

Minha opinião, bom... eu sou a favor do movimento feminino, feminista não. Porque eu sou feminina, entendeu? O feminismo só se for em busca de um todo. Sabe, no feminista, o individualista, eu não sou nada individualista. Eu sou muito no total, na soma dos dois, entendeu? Eu acho que se o movimento feminista for para engrandecer a família, engrandecer o trabalho, engrandecer os amigos, sim. Agora feminista voltada apenas pra competir, aí não. 
Porque eu acho que todos dois são bons no que fazem, em caminhos paralelos (M2).

Tal fragmento demonstra não só a oposição entre feminista e feminina, mas também uma visão do feminismo como um movimento segregacionista. Ou seja, considera-se que o mesmo esteja reivindicando direitos de uma forma individualista e voltada para a competição entre homens e mulheres, visão esta que será discutida adiante. A diferenciação entre a noção de feminismo e de feminino fica ainda evidente quando M4 afirma que "quem se submete ao machismo é porque ainda não cresceu interiormente. Ainda não é feminina o suficiente. Porque antes de ser feminista, você tem que ser feminina. Você tem que ser mulher, você tem que se amar. Se você não se ama, você vai dar espaço pra essas pessoas né... abusarem da sua feminilidade" (M4).

Observa-se a visão pejorativa que se atribui ao feminismo, e que foi discutida por Schmidt (2006). Atribui-se uma visão masculinizada às feministas, contrariamente ao que seria ser feminina. Para Nogueira (2001, p. 9), "se ser feminista, implica, no discurso tradicional, ser uma mulher mal amada, desinteressante do ponto de vista sexual, com problemas de relacionamento interpessoal, ou lésbica, as mulheres podem optar por ser verdadeiras mulheres, afastando-se assim deste estereótipo limitativo". Para o autor, a frase "Eu não sou feminista, mas..." representa a tentativa de muitas mulheres de se distanciarem dos estereótipos ligados à caricaturização do feminismo que é veiculada pela ideologia tradicional, aceitando, no entanto, a existência de alguns problemas.

Para Singer (1981), muitas reivindicações podem ser femininas, mas só são feministas quando discutem o modo como a mulher é inserida no contexto social. Tomando como perspectiva o caráter feminista erigido pelo autor, as mulheres que apresentam visões reducionistas do feminismo e que o rejeitam estão também negando a necessidade de questionamento de uma condição social ainda injusta.

As raízes da visão apresentada pelas mulheres entrevistadas em relação ao feminismo, embora tenham vivenciado muitas conquistas do movimento no Brasil, podem residir na própria repercussão que houve no país de uma conotação antifeminina ao feminismo. Para Sarti (1998), essa imagem do feminismo versus o feminino atingiu o movimento internamente, dividindo-o. Assim, dissemina-se a visão sobre as noções de feminismo e feminino como opostos e como, necessariamente, incompatíveis.

Em segundo lugar, observou-se, na percepção das mulheres entrevistadas, uma associação entre feminismo, segregação e radicalismo. Segregação devido a uma visão de que o movimento reivindique injustamente direitos, em prol apenas de uma parcela da sociedade, como se não houvesse já uma condição de opressão vivida pelas mulheres em uma sociedade de bases patriarcais. Além disso, o termo feminismo remete, para essas mulheres, quase sempre ao radicalismo do movimento. Quando questionada sobre a opinião que possui acerca dos movimentos feministas, M3 responde da seguinte forma:

Olha...eu acho que todo movimento em defesa de uma determinada postura que traga benefícios sabe, é bom. Agora todo movimento que radicaliza uma única percepção é... corre o risco de se perder sabe? Então, o movimento feminista...ele... ele cumpre um papel importante na sociedade...e ele vai ser...tanto mais importante na medida que ele não seja elemento de separação, de distanciamento, de radicalização das suas posturas, de exclusão (M3).

Também quando questionada sobre o que pensa em relação ao machismo, M3 respondeu que: 
São formas de autoafirmação que radicalizam por uma necessidade de impor um determinado espaço né. É... um espaço que deveria vir muito mais de uma relação interpessoal positiva do que de um confronto que muitas vezes é necessário né...no sentido evolutivo. Eu acho que um dia nós vamos chegar lá e não vai haver necessidade nem de movimento feminista, de machismo sabe, que os homens e as mulheres não vão ter necessidade de se autoafirmar sabe, mais num sentido de uma cooperação (M3).

Além de enfatizar o movimento como algo radical e como algo que considera apenas uma percepção, observa-se que M3 se refere ao movimento feminista como um tanto equiparado ao machismo, na sociedade. Tal equiparação também é feita por M1 no seguinte trecho de seu discurso:

Então, assim, eu não vejo assim como é...diferenças mesmo marcantes entre o homem e a mulher, não. Eu vejo diferenças de temperamento entre as pessoas né. Agora, nós temos o aspecto social né...a cultura tá aí...muito impregnada de machismo e feminismo. E...e nós temos que desmistificar...nós é que vamos mostrar que nós somos mulheres...capazes...educadas, não é? Polites, somos capazes de resolver nossos problemas em conjunto (M1).

A equiparação fica ainda mais forte quando M1 utiliza o termo "impregnada" de machismo e de feminismo, como se os dois fossem conceitos da mesma natureza, porém, atuando em sentidos opostos. O que é inadequado, já que o feminismo não pretendia impor a superioridade ou a dominação feminina sobre o homem. Na verdade, tinha como objetivo a equiparação dos sexos em relação ao exercício de direitos cívicos e políticos, após uma condição histórica de opressão vivenciada pelas mulheres. De fato, o movimento denuncia, nesse sentido, práticas que fazem com que pessoas, por serem pertencentes a um sexo, sejam inferiores em relação ao acesso a direitos e à liberdade (NOGUEIRA, 2001, p. 4).

Ilustrando essa visão equivocada do feminismo como demasiado radical, o trecho do discurso de M1, quando questionada sobre a opinião que possui sobre os movimentos feministas, serve como exemplo:

É... [risos] eu já até falei um pouquinho né...que eu não sou muito adepta de movimentos feministas desses radicais não. Porque a história deles geralmente começou com a emancipação total da mulher né. E...isso fez uma confusão na cabeça das mulheres, acho que as mulheres pensaram assim...agora eu posso... todas vamos fumar! Isso é importante...eu passei por essa fase...de pegar o cigarro pra eu dizer que eu era...era...como é que chama... tão competente quanto o homem... pra poder fumar, olha que bobeira. Adolescência...autoafirmação, não é. Então, assim...eu acho que os movimentos feministas teve um traço assim....um encaminhamento... foi um encaminhamento muito radical. E tudo que é radical tem prós e contras. Mas o radicalismo...ele é terrível né...e os movimentos feministas...eles embrenharam pra um lado que eu acho um pouco perigoso... que é a questão assim da independência total da mulher, sem precisar do companheiro tá? Ninguém vive sozinho...ninguém é uma ilha (M1).

Pode-se considerar que a percepção apresentada por M1, uma mulher que vivenciou o auge do movimento feminista brasileiro nos anos 70 , seja limitada, já que caracteriza o movimento como reivindicador de uma independência total das mulheres. Tal independência é interpretada pela entrevistada no sentido de viver sozinha e isolada, o que não condiz com a essência do movimento. Contudo, a referida visão pode se justificar tanto pelo modo como foi internalizado, pela entrevistada, o sen- 
tido do movimento em um âmbito mais pessoal, como também pelo próprio modo pelo qual se deu sua repercussão no Brasil. A imprensa brasileira, transmitia uma visão muitas vezes unificadora do movimento, homogeneizando-o, ainda que este fosse um tanto diversificado (CORRÊA, 2001). Além disso, torna-se necessário considerar a forma com que as mulheres, na época, interpretaram o movimento, inclusive com atitudes mais radicais, como a citada por M1. Deve-se atentar, nesse sentido, para a não generalização e unificação das percepções sobre o movimento. Ou seja, embora haja a repercussão de visões limitadas, o alerta é demonstrar como tais visões influenciaram de forma significativa a percepção das mulheres, que são o foco de atenção do movimento feminista.

A percepção das mulheres entrevistadas demonstra a visão do senso comum sobre o feminismo no país discutida por Schmidt (2006). A autora afirma justamente que:

Não é de hoje nem de ontem que o termo feminismo sofre uma sistemática depreciação e deslegitimação nos mais diversos círculos letrados do país. Via de regra, o uso do termo vem atrelado a certos sentidos do feminismo associados ao movimento de mulheres dos anos 60, os quais são destacados e universalizados [...]. Estou me referindo à assimilação de algumas ideias pelo senso comum esclarecido, as quais se cristalizam na representação do feminismo como um movimento extremista de libertação das mulheres [...] sustentado por uma ideologia [...] monolítica, autoritária [...] e, o que é pior, empenhada na transformação da mulher, destituindo-a de suas características femininas (SCHMIDT, 2006, p. 765, grifo da autora).

Schmidt (2006) reconhece que vulgarizar o feminismo é uma estratégia utilizada por alguns segmentos da elite intelectual, bem como associá-lo à marginalidade e ao anacronismo, como se o mesmo não fosse desejável para a sociedade brasileira. Tal estratégia acaba por desqualificar os avanços que permitiram as conquistas feministas nas últimas décadas. A disseminação de visões reducionistas do feminismo faz com que se desconsidere a importância de um movimento que, no Brasil, "enfrentou o autoritarismo da ditadura militar, construindo novos espaços públicos democráticos, ao mesmo tempo em que se rebelava contra o autoritarismo patriarcal presente na família, na escola, nos espaços de trabalho, e também no Estado (COSTA, 2005, p. 26-27).

Ainda, a visão observada de que o feminismo seja reivindicador de interesses específicos de uma classe, em detrimento de outra, justifica-se pelas acusações comuns às feministas de serem "divisionistas e defensoras de lutas específicas e menos importantes" (PEDRO, 2006, p. 267). Porém, para Pedro (2006), não se justifica atribuir ao feminismo primordialmente uma visão de lutas específicas, pois, a partir do momento em que é um movimento social de cunho libertário, busca uma totalidade no que se refere a um processo de transformação. A especificidade poderia estar, assim, apenas em contextos históricos diferentes. Uma vez que, apesar de haver diferentes grupos e diferentes tendências dentro do movimento feminista, sua causa não poderia ser considerada discriminatória, por exemplo, em relação aos homens. Soares (1998) também contribui para reforçar tal convicção ao defender que o feminismo se expressa em ações coletivas, individuais e existenciais; na arte, na teoria e na política.

Por esse motivo, o feminismo não pode ser considerado benéfico apenas para as mulheres, pois não deu visibilidade apenas às mesmas ou às questões femininas, já que denunciou e criticou formas de exclusão que ocorrem na esfera pública. Além 
disso, contribuiu para a construção de relações menos desiguais entre os sexos e, mais ainda, no que se refere ao exercício da cidadania (RAGO, 1995).

Contudo, a atribuição, pelas mulheres entrevistadas, de características radicais ao movimento não se delimitou apenas às questões até então discutidas. Observaram-se também visões radicais em relação ao movimento, como sua associação ao homossexualismo (lesbianismo). M4, por exemplo, demonstrou acreditar que as relações homossexuais tenham crescido em virtude dos movimentos feministas:

E aí...as relações homossexuais também cresceram muito... isso, a gente tem uma base nos movimentos feministas. É...quê isso, não preciso de homem pra nada! Né...eu sou capaz de me auto gerenciar. Não, mas a gente... eu acho assim..a gente precisa de um colo...tem que chorar no colo do marido...sabe? Tem que desejar o homem e vice-e-versa...o homem desejar a mulher. Isso não vai acabar não, sabe? Essa...a...nenhum preconceito vai aqui em relação à homossexualidade não...eu vejo a homossexualidade como escolha tá? Mas eu vejo muito da mulher e do homem no cultural também, no social, muito influenciado pela mídia...e pelos movimentos tá (M4)?

Além de considerar que os movimentos tenham incentivado, de certa forma, as relações homossexuais, M4 reforça a visão de que adequar-se ao movimento seria o mesmo que declarar uma independência afetiva em relação ao homem. Ainda, quando diz que "tem que desejar o homem e vice-e-versa", demonstra a visão de que, supostamente, uma feminista não desejaria um homem, já que quer declarar independência em relação ao mesmo. A associação do movimento com o lesbianismo já era destacada por Rago (1995) quando compara a associação da figura feminis- ta às concepções misóginas vitorianas sobre a sexualidade feminina, em que a feminista estaria relacionada à histeria, ao furor uterino, à incapacidade de ser amada pelo homem, entre outras.

Dessa forma, observa-se uma visão de que, historicamente, o movimento feminista poderia ter desencadeado o crescimento da homossexualidade na sociedade, já que se considera erroneamente que ela seja uma escolha influenciada inclusive pela mídia. Nesse sentido, as entrevistadas demonstraram enxergar o feminismo como forma de embrutecimento das mulheres, o que é uma visão duplamente limitada. Primeiro, é uma visão reducionista em relação ao próprio movimento. Segundo, é uma visão limitada em relação às próprias homossexuais, estereotipando-as como necessariamente masculinizadas. Nesse sentido, M1 descreveu que:

Porque quando a mulher...veio a minissaia, advento da pílula e...e a participação da mulher mais ativa na sociedade...isso significou talvez assim é... primeiro, a mulher masculinizou-se. Então, tinha esse...aí era uma feminista. Era uma Betty Friedan, tá vendo, olha lá...sabe por que ela defende as mulheres? Porque ela é horrorosa, porque ela não tem feminilidade, ela embruteceu. Ela quer ter os mesmos direitos do homem, ela quer ir pro bar...virar a noite. [...] por isso que eu te falo...eu não sou feminista...e feminista nesse sentido (M1).

Nota-se, então, a noção de feminismo atribuída à mulher embrutecida, desprovida de beleza, ou que não exerce sua feminilidade. Ainda, o estereótipo de homem como bruto e a mulher como o oposto, como se participar do movimento feminista fosse o que restasse para aquelas mulheres consideradas feias. Betty Friedan, citada por M1, foi uma importante ativista feminista, cuja obra inaugurou o movimento feminista nos EUA, na década de 1960 (SARTI, 2004). Na mesma linha, M4 declara: 
[...] eu acho que os movimentos feministas influenciaram muito pra que as mulheres ficassem independentes masculinizadas, não é? É.. desde a roupa...o uso da roupa...por exemplo, o advento da calça jeans... da calça comprida, não é? E eu passei por isso tudo... posso te dizer... até...é...hábitos e costumes. Então, a mulher quis, é... se igualar ao homem. Não existe isso [risos], cada um é um, tem uma essência (M4).

Confunde-se, nesse sentido, a luta pela igualdade política e social entre homens e mulheres com a suposta luta pela igualdade de costumes, de modos e de vestimentas. Assim, as visões apresentadas pelas mulheres se revelaram altamente estigmatizadas em relação às reivindicações e às posturas feministas. E com os resultados da pesquisa, percebe-se o que Rago (1995) já anunciava, que é a não dificuldade em se ouvir as próprias mulheres reafirmando os estigmas das feministas como "mulheres feias, infelizes e sexualmente rejeitadas pelos homens" (RAGO, 1995, p.11).

Além de se enfatizar o caráter radical do feminismo, percebe-se que a visão apresentada pelas mulheres está de acordo com o que Hawkesworth (2006) critica, que é a tradução do feminismo exclusivamente em termos de movimento social, descartando todas as suas outras dimensões.

Traduzir o feminismo exclusivamente em termos de movimento social joga com a fascinação da mídia pelo espetáculo, mas tem o efeito desagradável de permitir aclamações de morte quando as mulheres não estejam mais nas ruas. Confundir o feminismo com formas de protesto e demonstrações de massa mantém uma representação do feminismo como um perpétuo outsider [...] muito antes de as feministas terem alcançado as transformações sociais que almejaram. O movimento é considerado morto enquanto as feministas continuam a luta para alcançar sua agenda não concretizada (HAWKESWORTH, 2006).

Além disso, nota-se que, para as mulheres entrevistadas, ser feminista implicaria necessariamente participar do movimento social em si e levantar uma bandeira que seria injusta em relação ao homem. Porém, com base em Hawkesworth (2006), considera-se que a identidade feminista independe da aceitação de uma ideologia formulada por outros. Muito mais que isso, torna-se uma causa existencial quando a mulher passa a lutar para vencer as desigualdades e as contradições que a oprimem.

Tal luta seria exatamente o feminismo enquanto práxis, discutido por Hawkesworth (2006). Como práxis, o movimento se situaria na política da vida diária. Outra possível saída para a fuga dessas visões reducionistas sobre o feminismo seria considerá-lo em um sentido mais amplo, "[...] como todo gesto ou toda ação que resulte em protesto contra a opressão e a discriminação da mulher, ou que exija a ampliação de seus direitos civis e políticos" (DUARTE, 2003, p.152).

Porém, pelo que se observa, a visão dessas mulheres sobre o feminismo ainda se distancia desse sentido mais amplo, que pode abarcar suas diversas facetas. As entrevistadas não deixam de reconhecer alguns avanços relativos à condição da mulher, mas não discorrem sobre esses avanços de forma a reconhecer a importância da pressão feminista para as conquistas alcançadas. Por exemplo, questionada se acredita ter mudado algo na relação entre homens e mulheres na sociedade, M4 responde que:

Ah sim, com certeza né. A mulher... ela tá sempre conquistando um espaço a mais né...com a evolução...com a própria evolução das coisas né, com a mulher...hoje ela tá inserida 
dentro do círculo militar, tá inserida em determinadas áreas que antes a mulher não atuava né. Não tinha espaço, isso com certeza cada dia que passa tá...é..demonstrando que ela é capaz de...fazer né...tanto atividades voltadas pra homem quanto pra mulher né (M4).

Há uma contradição no discurso de M4, pois, ao mesmo tempo em que rejeita a igualdade entre homens e mulheres relativa ao comportamento, ao modo de se vestir e de agir, quando discorre, em trecho anteriormente apresentado, que "a mulher quis, é... se igualar ao homem. Não existe isso [risos], cada um é um, tem uma essência"; demonstra valorizar o fato de a mulher mostrar-se capaz de fazer atividades que seriam direcionadas para os homens. Ainda, nessa fala, não se atribui ao feminismo tais conquistas.

Além disso, algumas das conquistas atribuídas ao movimento são consideradas de forma pejorativa, principalmente as relativas à liberdade sexual e ao direito da mulher de decidir ter ou não filhos:

Essa questão da emancipação da mulher, que veio com o advento da pílula anticoncepcional, na década de..., eu passei por isso tudo, na década de 70, da sexualidade. É... eu acho que isso vulgarizou um pouco a mulher. A mulher entendeu isso como uma liberação total e na realidade... não é isso. Ela tem que saber usar a liberdade dela, ela tem que saber se respeitar, ela tem que saber se gostar. Quem não gosta de si não gosta dos outros. E isso começa pelo corpo não é? As mulheres...você não pode ir na universidade como você vai pra uma praia, não é? [...] Porque ali não é um lugar... mesma coisa você entrar em um templo religioso nua (M1).

Observa-se, no referido trecho, que se atribui, ao advento da pílula anticoncepcional e à maior liberdade em termos de sexualidade para a mulher, extrapolações de limites morais relativos ao uso da roupa e ao cuidado com a imagem do corpo, desvirtuando o caráter positivo que tais conquistas representaram para as mulheres em relação ao direito de decisão sobre o próprio corpo e sobre a sua sexualidade, o que já era em contrapartida conferido aos homens. Pelo discurso, a possibilidade de liberdade individual das mulheres, capazes de decidir o que fazer ou não com seu próprio corpo e com suas atitudes, fica limitada a uma condição moral. Assim, não só se considera o lado negativo de uma conquista do movimento feminista, como também se continua não atribuindo ao mesmo tal conquista.

Analisando-se o discurso das mulheres entrevistadas, observa-se uma possível causa para a desconsideração da contribuição do movimento feminista para a conquista de direitos das mulheres: as entrevistadas enfatizam o caráter interpessoal dos avanços relativos à condição da mulher na sociedade e a relação entre homens e mulheres. Talvez, nesse sentido, possa-se observar uma visão do feminismo não diretamente identificado e reconhecido como práxis e não somente como movimento social. Embora já se tenha dito que a visão dessas mulheres se atenha mais ao feminismo como movimento, alguns discursos permitem revelar a importância que atribuem às ações diárias das mulheres em contraposição à sua condição de opressão. Contudo, ainda que considerem tais ações cotidianas e a prática, não identificam, nas mesmas, também o feminismo. Por isso se diz que feminismo, para essas mulheres, é somente o movimento social.

Exemplificando o caráter interpessoal atribuído às conquistas, M1, quando questionada se acredita que houve alguma mudança na relação entre homens e mulheres na sociedade, responde:

Mãe de deus... .mãe de deus. Desses anos todos que passei, desde 
a independência financeira até as questões relacionadas ao trabalho, a relacionamento homem e mulher... a mulher não tomava a iniciativa na relação. Hoje não, a mulher toma a iniciativa, a mulher é capaz de dizer: hoje eu não quero, não quero me relacionar com você, estou cansada pô, trabalhei o dia inteiro, faxinei, fiquei em pé o dia inteiro [...], hoje eu não quero, não estou com vontade. Mas houve época que não, a mulher era extremamente submissa, há ainda muitas mulheres submissas... que tem vergonha... eu conheço, gente, mulher que não pega táxi, com medo do taxista, existe... pasme. Existe (M1).

Ou seja, M1 reconhece claramente a conquista da mulher relativa à sua possibilidade de escolha, de manifestação de suas vontades e de não submissão à vontade do homem, embora, como declara, haja ainda mulheres que sejam submissas. No entanto, não cita o feminismo enquanto motivador dessas conquistas, que recaem para um nível interpessoal, o que seria o feminismo enquanto práxis.

Outra entrevistada, M2, restringe a liberdade das mulheres também a uma dimensão de comportamento pessoal, não a relacionando a estruturas sociais existentes ou a possíveis barreiras, como se a liberdade dependesse apenas de sua própria postura. Ao ser questionada sobre o que seria liberdade para as mulheres, responde:

Liberdade? [risos] Essa... essa é difícil [risos] porque eu sou livre [gargalhadas]. Aí eu não me imagino sem a liberdade, entendeu? Eu sou livre e eu faço o que eu quero. Logicamente, até onde vai o direito dos outros. Então eu sou brincalhona, ninguém duvida de mim porque sabe que eu faço tudo, entendeu? De brincadeira então, nossa mãe. Você nem calcula o quê que eu faço. Então, o impossível pra mim não existe. Eu faço tudo, então a li- berdade... eu acho que está nas conquistas que você faz dentro de você. $\mathrm{E}$ as pessoas que estão ao seu redor... as pessoas sabem que você faz porque você gosta, certo? Então eu não tenho vergonha de fazer nada, a não ser andar pelada pela rua, aí também [risos]. Aí já é invadir o direito dos outros. Mas eu não tenho limite com a minha liberdade. [...] Agora a liberdade pra mim é tudo...tudo pra mim a liberdade (M2).

Dessa forma, como dito, liberdade para M2 depende apenas de sua própria vontade de ser livre. Quando se considera a liberdade nesse sentido, não se reconhece as lutas que tiveram que ser travadas, pelas mulheres, contra uma estrutura social em que prevalecia a dominação masculina. Questiona-se: será que M2 não reconhece que, para que atualmente, como mulher, possa se declarar tão livre como o faz, algumas conquistas tiveram que ser buscadas inclusive e principalmente pelos movimentos feministas? M2 demonstra-se audaciosa ao falar de liberdade, não reconhecendo que algo a possa impedir de fazer o que deseja. Quando diz que não pode apenas "andar pelada pela rua", retorna à visão radicalista da reivindicação das mulheres e aproxima-se da já discutida questão da liberdade sexual. M3 também apresentou uma visão de liberdade afim com a de M2, reforçando a análise aqui discutida:

Olha...eu não vejo liberdade pra mulher e liberdade pro homem...acho que existe a questão de liberdade. E, ao meu ver, está muito mais condicionada a opções que a gente faz... [...] em uma determinada cultura, tem determinados padrões que podem me limitar mais ou podem me limitar menos, mas são sempre possibilidades que eu tenho de escolher. Qualquer que seja a situação, uma escolha que eu faço... tanto eu como mulher, como alguém como homem, já de certa forma elimina série de outras possibilidades... essa capacidade 
da escolha é que seria a liberdade que a gente tem $[\ldots](\mathrm{M} 3)$.

Mais uma vez, condiciona-se a liberdade às escolhas dos indivíduos. A visão de M3 pode ser considerada adequada em relação a uma não diferenciação entre liberdade para homens e para mulheres. Mas observa-se, ainda, uma não consideração, no discurso dessas mulheres, das históricas restrições à liberdade das mulheres, ao serem questionadas sobre o tema. Quando M3 fala de padrões culturais que podem limitar mais ou menos as ações de um indivíduo, ainda assim, deixa como foco principal a escolha desse indivíduo pelo caminho que lhe dará mais ou menos liberdade. Inclusive, M3, ao falar que não tem filhos, considera que sua liberdade seja maior que a liberdade de outras mulheres que os têm, condicionando o estar livre às opções que os indivíduos fazem ao longo de sua vida. Como psicóloga, observa-se que M3 reforça bastante a dimensão (inter) pessoal das mudanças nas relações entre homens e mulheres na sociedade, mais uma vez, deixando de citar possíveis contribuições de movimentos organizados de mulheres. A entrevistada, ao falar sobre as mudanças no comportamento da mulher, justifica-as pelo que chama de "processo evolutivo da humanidade" (M3).

Nota-se, assim, um reconhecimento dos avanços na condição social da mulher em um nível distante do político e mais próximo do pessoal. Corroborando com essa discussão, Costa (2005) argumenta que cresce, entre os movimentos sociais e algumas organizações autodenominadas equivocadamente como movimentos de gênero, um posicionamento que questiona a existência atual do feminismo e que coincide com a visão que as entrevistadas apresentaram. Por essa perspectiva, acreditam que seja possível mudar a sociedade e as injustiças apenas por meio de comportamentos individuais de homens e de mulheres.
Após uma breve revisão sobre a trajetória do movimento feminista brasileiro, bem como suas conquistas, é inevitável que se atribua ao posicionamento das mulheres entrevistadas um não reconhecimento de que o feminismo, ao politizar sobre desigualdades de gênero, transformou as mulheres em novos sujeitos políticos (CARNEIRO, 2003). De fato, as mudanças em níveis interpessoais são importantes, como por exemplo, no que se refere às duplas jornadas de trabalho enfrentadas atualmente pelas mulheres, há que se reeducarem os homens para que eles sejam efetivamente parceiros, iguais tanto em situações afetivas quanto em familiares (NOGUEIRA, 2001). Porém, apenas mudanças interpessoais não são necessárias, pois se torna importante o retorno às iniciais reivindicações dos movimentos feministas de que o pessoal também é político, já que a situação das mulheres envolve relações de poder socialmente estabelecidas.

Apesar de este estudo ter sido realizado com mulheres que foram o alvo das sensibilizações iniciais e recursos de ordem simbólica do feminismo, ou seja, "mulheres profissionais, com educação universitária, pertencendo a camadas sociais com alguma experiência de vida cosmopolita, associadas [...] à formação educacional e profissional" (SARTI, 2001, p. 43), encontrou-se uma perspectiva que pode ser considerada reducionista, limitada e muitas vezes pejorativa sobre o feminismo. As mulheres entrevistadas não reconhecem as ricas nuances que o feminismo, como movimento, teoria, práxis, conjunto de ideias ou ideologia apresentou. Muitos podem ser os fatores apontados para tais visões, como se pôde observar ao longo da consideração de alguns autores sobre as visões de senso comum existentes, talvez pela identidade ambivalente do sujeito no feminismo (COSTA, 2002), ou também pela própria difusão de uma imagem negativa do movimento pelos meios de comunicação, bem como a pro- 
pagação, em meados da década de 80 , de que o mesmo estaria fora de moda (NOGUEIRA, 2001, grifo do autor).

Certamente, os resquícios de difusões equivocadas, ou simplesmente limitadoras, do que seria o feminismo ou de qual seria sua importância na sociedade se fazem presentes nos discursos das mulheres entrevistadas em meio ao século XXI. Vale observar também que o feminismo enfrentou duras resistências desde seu início por questionar ordens vigentes e certamente os detentores do poder formulariam suas estratégias para que a imagem do mesmo fosse negativa para a sociedade como um todo.

\section{Considerações finais}

Com o presente estudo, percebe-se que, desde a origem de seu termo, o feminismo enfrenta duras resistências, e as que mais se concretizam até tempos atuais são as que dizem respeito à construção de uma imagem negativa do movimento, mesmo para mulheres que vivenciaram o seu auge no país e, principalmente, foram impactadas pelas mudanças para as quais o movimento contribuiu. Observa-se também, como já afirmava Rago (1995), que alterações que se deram no campo das relações de gênero não foram acompanhadas por uma crescente valorização do feminismo. Muito pelo contrário, há, por muitos, a declaração de sua morte.

Porém, torna-se necessário reconhecer que, mesmo o feminismo tendo incorporado uma diversidade de discursos e mesmo havendo uma variedade de feminismos (COSTA, 2002), tal heterogeneidade não significa seu enfraquecimento nem mesmo a redução de sua importância política, pois essa diversidade apenas abre espaço para as diferentes realidades que englobam a condição da mulher nos espaços sociais.

Ressalta-se que o posicionamento adotado no presente artigo, para analisar o discurso das mulheres entrevistadas, atende à reivindicação de Ribeiro (2006, p. 809), que é "reforçar o movimento feminista enquanto movimento produtor de ideias e de práticas inovadoras, que questionam a estrutura social vigente". Optou-se por não utilizar construções estereotipadas do movimento feminista como um movimento de mulheres tristes, frustradas e incapazes de conquistar o sexo forte, que seria a estratégia de supervalorização das iniciativas feministas sob um olhar heróico, sem considerar o contexto das mesmas em relação a quadros de reflexão e de atuação (RAGO, 1995). O posicionamento aqui adotado não pretendeu, portanto, apresentar um movimento heróico, mas reconhecer que o mesmo é um "movimento social, político e intelectual que teve um profundo impacto na sociedade brasileira e no mundo" (RAGO, 1995, p. 12).

Considera-se preocupante a visão das mulheres investigadas. Muitos desafios ainda precisam ser enfrentados, como por exemplo, o enorme caminho a trilhar relativo à violência doméstica contra a mulher, ao assédio sexual, ao estupro e a tantas outras formas de violência física, psíquica e social. Acrescenta-se também a garantia de instrumentos para a efetivação de leis de proteção às mulheres e o combate às desigualdades ainda sofridas por elas no mercado de trabalho. No âmbito dos estudos organizacionais, é importante ampliar e aprofundar investigações sobre o fenômeno "teto de vidro" nas organizações (STEIL, 1997), que impede ou dificulta a ascensão das mulheres no mercado de trabalho, bem como a pressão que elas sofrem com duplas ou triplas jornadas diárias. Observa-se que ainda persiste relativa "[...] distância entre a igualdade legal formal e a política e a prática de todos os dias. Os direitos e os princípios mantiveram-se teóricos, especialmente em termos socioeconômicos e no que diz respeito às vidas privadas das mulheres" (NOGUEIRA, 2001, p. 7). 
Desse modo, questiona-se até que ponto as entrevistadas rejeitam o feminismo como um movimento que enfraquece a feminilidade, eventualmente associada a comportamentos mais aceitos pela sociedade como passividade, recato e atuações discretas no espaço público. Um paradoxo observado é que, para serem bem sucedidas como empreendedoras, utilizam de comportamentos ainda considerados masculinos, tais como: a racionalidade, a capacidade de negociação, a facilidade de lidar com números e a exploração de potencialidades econômicas diversas. A apropriação desses comportamentos pelas mulheres se fez possível em função da atuação marcante de lideranças femininas que enfrentaram, a partir da década de sessenta, discriminações, violências, precarização de relações de trabalho e todo tipo de desqualificação de suas bandeiras de luta.

No entanto, ainda há muito que se avançar na busca por igualdade, com desafios contemporâneos relativos a conquistas não universais e mais situadas entre as mulheres do Ocidente, como também a uma baixa incidência de divisão de tarefas relativas a responsabilidades domésticas ou de educação e cuidado com crianças pelos casais (NOGUEIRA, 2001). A rejeição do que se entende por feminismo, na concepção das entrevistadas, pode bloquear novos avanços.

Sob essa perspectiva de análise, se as desigualdades persistentes estão intrinsecamente relacionadas a estruturas de poder predominantes na sociedade, algumas indagações se tornam possíveis. Por que não valorizar as reivindicações e a trajetória do feminismo, seja como movimento social, práxis, ideologia ou seja como um conjunto de convicções?

É fundamental reforçar que um dos principais campos de atuação do feminismo atual é a reivindicação pela ampliação de espaços políticos. No entanto, mesmo no processo de ocupação pelas mulheres de todos os espaços da sociedade, como o "poder público, o parlamento, os meios acadêmicos, as associações, os partidos, os movimentos sociais" (RIBEIRO, 2006, p. 809), tal "ocupação vem acompanhada de inúmeras dificuldades nem sempre recheada de poder" (RIBEIRO, 2006, p. 809). Assim, pode-se considerar que "apoiar" os movimentos feministas possa ser algo importante tanto para a efetivação de conquistas anteriores, como para o alcance de outras ainda necessárias.

As entrevistas realizadas com as quatro mulheres produziram um corpus interessante para que se possa entender, ainda que embrionariamente, os processos que fizeram com que essas mulheres polarizassem feminismo e feminilidade como situações antagônicas. A realização cuidadosa das entrevistas possibilitou a obtenção de informações aprofundadas sobre o que se pretendia.

Como sugestões para futuros trabalhos, indica-se investigar a visão que mulheres de outras classes sociais apresentam sobre o movimento feminista. Um estudo realizado com mulheres de baixa renda, por exemplo, poderia trazer outras perspectivas para enriquecer a análise, já que a situação "da mulher que se emancipou, graças às conquistas feministas de gerações anteriores, [...] ainda é privilegiada em comparação com as das mulheres das classes trabalhadoras: a operária, sobretudo a casada e com filhos, a empregada doméstica, a dona-de-casa pobre, sem falar das mulheres abandonadas pelo marido, das viúvas, das prostitutas etc." (SINGER, 1981, p. 111). Assim, essa seria uma possibilidade interessante para futuras investigações sobre a imagem de um movimento que deixou marcas significativas na sociedade brasileira e que ainda está por aí, pois, ainda que haja os que declarem sua morte, seu enterro ainda não ocorreu, já que os espaços para as feministas se ampliam cada vez mais. Mas qual será a denominação para aquelas que ocuparem tais espaços? Feministas ou femininas? 


\section{Referências bibliográficas}

ALVAREZ, S. Feminismos latinoamericanos: reflexiones teóricas y perspectivas comparativas. In: RIOS TOBAR, M. (Org.). Reflexiones teóricas y comparativas sobre los feminismos em Chile y America Latina. Santiago: Notas del Conversatorio, 1998. p. 4-22.

BAIRROS, L. Nossos feminismos revisitados. Revista Estudos Feministas, v. 3, n. 2, p. 458-463, 1995.

BARSTED, L. A. L. Em busca do tempo perdido: mulher e políticas públicas no Brasil 1983-1993. Revista Estudos Feministas, v.0, n. especial, p. 38-53, out. 1994.

BORDO, S. A feminista como o Outro. Revista Estudos Feministas, v. 8, n. 1, p. 10-29, 2000.

CARNEIRO, S. Mulheres em movimento. Estudos avançados, v. 17, n. 49, p. 117-133, 2003.

CORREA, M. Do feminismo aos estudos de gênero no Brasil: um exemplo pessoal. Cadernos Pagu, n. 16, p. 13-30, 2001.

COsTA, A. A. A. O movimento feminista no Brasil: dinâmicas de uma intervenção política. Revista Labrys, Brasília, v. 7, p. 09-35, 2005.

COSTA, A. O. Os estudos da mulher no Brasil ou a estratégia da corda bamba. Estudos Feministas, n. especial, p. 404-409, 1994.

COSTA, C. L. O sujeito no feminismo: revisitando os debates. Cadernos Pagu, n. 19, p. 59-90, 2002.

SOUZA, E.; BALDWIN, J. R.; ROSA, F. H. A construção social dos papéis sexuais femininos. Psicol. Reflex. Crit., v. 13, n. 3, p. 485-496, 2000.
DUARTE, C. L. Feminismo e literatura no Brasil. Estudos Avançados, v. 17, n. 49, p. 151-172, 2003.

FRANCHIETTO, B.; CAVALCANTI, M. L. V. C.; HEILBORN, M. L. Antropologia e feminismo. Perspectivas Antropológicas da Mulher, Rio de Janeiro, v. 1, n. 1, p. 11-47, 1981.

GODOY, A. S. Introdução à pesquisa qualitativa e suas possibilidades. Revista de Administração de Empresas, v. 35, n.3, p. 20-29, maio/jun., 1995

HAWKESWORTH, M. A semiótica de um enterro prematuro: o feminismo em uma era pós-feminista. Revista Estudos Feministas, v. 14, n. 3, p. 737-763, 2006.

MARIANO, S. A. O sujeito do feminismo e o pós-estruturalismo. Revista Estudos Feministas, v. 13, n. 3, p. 483505, set./dez. 2005.

NOGUEIRA, C. Feminismo e discurso do gênero na psicologia social. Psicologia e Sociedade, v. 13, n. 1, p. 107-128, 2001.

PEDRO, J. M. Narrativas fundadoras do feminismo: poderes e conflitos (1970-1978). Rev. Bras. Hist., v. 26, n. 52, p. 249-272, 2006.

RAGO, M. .Adeus ao feminismo? Feminismo e pós-modernidade no Brasil. Cadernos AEL, n. 3/4, p. 12-43, 1995/1996.

RIBEIRO, M. O feminismo em novas rotas e visões. Revista Estudos Feministas, v. 14, n. 3, p. 801-811, 2006.

SARTI, C. A. Feminismo e contexto: lições do caso brasileiro. Cadernos Pagu, n. 16, p. 31-48, 2001.

SARTI, C. A. Feminismo no Brasil: uma trajetória particular. Cadernos de Pesquisa, São Paulo, n. 64, 1988. 
SARTI, C. A. O início do feminismo sob a ditadura no Brasil: o que ficou escondido. In: CONGRESSO INTERNACIONAL DA LASA, 21., 1998, Chicago. Anais... Chicago: Illinois, set. 1998.

SARTI, C. A. O feminismo brasileiro desde os anos 1970: revisitando uma trajetória. Revista Estudos Feministas, v. 12, n. 2, p. 35-50, mai./ago. 2004.

SCHMIDT, R. T. Refutações ao feminismo: (des) compassos da cultura letrada brasileira. Revista Estudos Feministas, v. 14, n. 3, p. 765-799, 2006.

SCHMIDT, S. P. Como e por que somos feministas. Revista Estudos Feministas, v. 12, n. especial, p. 17-22, 2004.

SINGER, P. O feminino e o feminismo. In: SINGER, P. et al. São Paulo: o povo em movimento. Petrópolis: Vozes, 1980.

SOARES, V. Muitas faces do feminismo no Brasil. In: BORBA, A. et al.(Org.). Mulher e política: gênero e feminismo no Partido dos Trabalhadores. São Paulo: Perseu Abramo, 1998.

STEIL, A. V. Organizações, gênero e posição hierárquica: compreendendo o fenômeno do Teto de Vidro. Revista de Administração, São Paulo, v. 3, n. 32, p.62-69, jul./set., 1997. 